\title{
Baseline factors predictive of serious suicidality at follow-up: findings focussing on age and gender from a community-based study
}

\author{
A Kate Fairweather-Schmidt*1, Kaarin J Anstey², Agus Salim³ and Bryan Rodgers ${ }^{4}$
}

\begin{abstract}
Background: Although often providing more reliable and informative findings relative to other study designs, longitudinal investigations of prevalence and predictors of suicidal behaviour remain uncommon. This paper compares 12-month prevalence rates for suicidal ideation and suicide attempt at baseline and follow-up; identifies new cases and remissions; and assesses the capacity of baseline data to predict serious suicidality at follow-up, focusing on age and gender differences.

Methods: 6,666 participants aged 20-29, 40-49 and 60-69 years were drawn from the first (1999-2001) and second (2003-2006) waves of a general population survey. Analyses involved multivariate logistic regression.

Results: At follow-up, prevalence of suicidal ideation and suicide attempt had decreased (8.2\%-6.1\%, and 0.8\%-0.5\%, respectively). However, over one quarter of those reporting serious suicidality at baseline still experienced it four years later. Females aged 20-29 never married or diagnosed with a physical illness at follow-up were at greater risk of serious suicidality $(\mathrm{OR}=4.17,95 \% \mathrm{Cl}=3.11-5.23 ; \mathrm{OR}=3.18,95 \% \mathrm{Cl}=2.09-4.26$, respectively). Males aged $40-49$ not in the labour force had increased odds of serious suicidality $(\mathrm{OR}=4.08,95 \% \mathrm{Cl}=1.6-6.48)$ compared to their equivalentlyaged and employed counterparts. Depressed/anxious females aged 60-69 were nearly 30\% more likely to be seriously suicidal.

Conclusions: There are age and gender differentials in the risk factors for suicidality. Life-circumstances contribute substantially to the onset of serious suicidality, in addition to symptoms of depression and anxiety. These findings are particularly pertinent to the development of effective population-based suicide prevention strategies.
\end{abstract}

\section{Background}

In an effort to reduce prevalence of suicide and suicidal behaviours, many countries have mounted public health campaigns, such as the Australia's National Suicide Prevention Strategy[1]. The Australian Bureau of Statistics (ABS) documents all deaths due to suicide nationwide, and has recently published trends revealing a notable downturn in suicide deaths, most significant among young males[2]. Johnstone et al.[3] highlight that although it may be possible to acquire state-administered datasets that allow for disaggregation, the ABS does not administer central database records for non-fatal injuries (including attempted suicides) presenting to Accident

* Correspondence: kate.fairweather-schmidt@adelaide.edu.au

1 Freemasons Foundation Centre for Men's Health, The University of Adelaide, Adelaide, 5005, South Australia

Full list of author information is available at the end of the article and Emergency as, for instance, maintained by The Centers for Disease Control and Prevention in the United States of America. Further, Australian data are eventbased, not person-based, which results in difficulties in the calculation of population-based prevalence statistics[3]. These constraints present difficulties for those examining prevalence of non-fatal suicidal behaviour for a corresponding rate attenuation. As a partial consequence of lacking these data, there are no published studies in Australia that have longitudinally mapped rates of suicidal behaviour (as opposed to completed suicides) over time. This contributes to the difficulty in gauging the effectiveness of Australia's National Suicide Prevention Strategy (NSPS; LIFE framework) specifically in terms of non-fatal suicidality. Nonetheless, in a commentary paper reviewing the effect of the NSPS, Robinson et al. [4] sug- 
gest that the approach may be underperforming due to a lack of specificity.

Moscicki[5] provides a comprehensive review of general risk factors, however Fairweather et al.[6] highlight that some variables have a better predictive capacity within certain age or gender groups. This paper extends these works though epidemiologic longitudinal analysis by providing insight into whether these variables, predictive of suicidal behaviour, impact distally[7].

Epidemiological research using community-based surveys avoid bias problematic for investigations involving patient samples, providing more accurate profiles of suicidality in the wider population[8]. General population studies access particular individuals (e.g., suicidal) who may not otherwise be identified, providing valuable information about the community at large and facilitating targeted prevention and intervention programs $[9,10]$. Despite recently published papers utilising cohort population-based methods[11,12], these remain relatively scarce in suicidological research. Longitudinal designs are able to report incidence rates; measure change within individuals; and, overcome the impact of age differences upon cohort effects by sampling multiple age cohorts[13]. No longitudinal investigation, however, has sought to identify factors measured at baseline that are subsequently associated with the emergence of serious suicidal behaviour (i.e., ideation-plans-attempts) at follow-up specific for age-by-gender groups. The major focus on both life span and gender characteristics is anticipated to yield more targeted information relevant for populationbased prevention and intervention programs.

The present study has two objectives. First, to compare annual prevalence rates for suicidal ideation and suicide attempts at baseline and four years later; and, to compare new cases of and remission from serious suicidality (i.e., suicidal ideation, suicide plans, or suicide attempts). Second, to investigate variables measured at baseline (demographics, employment status, mental and physical health, personality, life stresses or social environment factors) that predict serious suicidality four years later for the total sample, and more specifically, separate age-by-gender groups.

\section{Methods}

\section{Participants and procedure}

The sample constitutes participants from both Wave 1 and Wave 2 of the PATH (Personality and Total Health) Through Life Project. For Wave 1 (commenced 1999, completed 2001), participation rate was $58.6 \%$ for those aged 20-24 (the 20s group), $64.4 \%$ for $40-44$ year olds (the 40 s group) and $58.3 \%$ for $60-64$ year olds (the 60 s group). Wave 2 (commenced 2003, completed 2006) maintained $89.0 \%$ of the 20 s group, $93.0 \%$ of the 40 s group, and $87.1 \%$ of the 60 s group. At Wave 1 there were 1,009 males and
1,119 females in the 20s group, 1,098 males and 1,246 females in the 40s group, and 1,134 males and 1,060 females in the 60s group. Figure 1 provides a flowchart detailing participation rate for Wave 1 and 2 of the PATH survey. Approval of The PATH Through Life Project protocol (No. M9807) was granted by The Australian National University Human Research Ethics Committee on $22^{\text {nd }}$ September 1998. Survey methodology has been published previously[14].

\section{Measures}

Sociodemographic variables involved current marital status (married/de facto, separated/divorced/widowed, never married), employment status (full-time, part-time, not in labour force), education (total years studying to highest qualification), parent (yes/no). Health and substance use was assessed by the Goldberg Depression and Anxiety Scales[15], the AUDIT scale evaluated alcohol use (abstain, occasional/light, medium, hazardous/harmful[16]), current tobacco smoker (yes/no)[17], and the frequency of marijuana usage was determined (don't use, once or twice per year, once every 1-4 months, once or more per week[18]). Physical health items established whether participant suffered from common chronic diseases[19]. A low prevalence of physical medical conditions necessitated the creation of a single binary variable indicating whether participants had been diagnosed with heart trouble, cancer, arthritis, or diabetes. Relationships and life stressor variables constituted participants' experiences of childhood adversity [20], the number of life events in the last 6 months [21], and two measures of negative interactions; one concerning family, and the other, friends[22]. The personality scales were Eysenck's Psychoticism (EPQ-P) scale and perceived level of mastery[23,24]. The outcome variable ascertained whether respondents had experienced serious suicidality. Serious suicidality was indicated by reporting experience of at least one of the following suicidal thoughts or behaviours during the past year: "Have you ever thought about taking your own life"; "Have you made any plans to take your own life"; and "In the last year have you ever attempted to take your own life?"[25].

\section{Data analysis \\ Descriptive statistics}

Comparisons of baseline and follow-up sociodemographic characteristics were undertaken separately for age group and compared within and between genders. Analysis of continuous variables required One-way Analysis of Variance (ANOVA); Pearson's Chi-Square $\left(\chi^{2}\right)$ test with Adjusted Residuals was utilised for categorical variables (SPSS Version 12). McNemar's Test determined significance of follow-up variation in suicidal ideation and suicide attempt prevalence at baseline. 


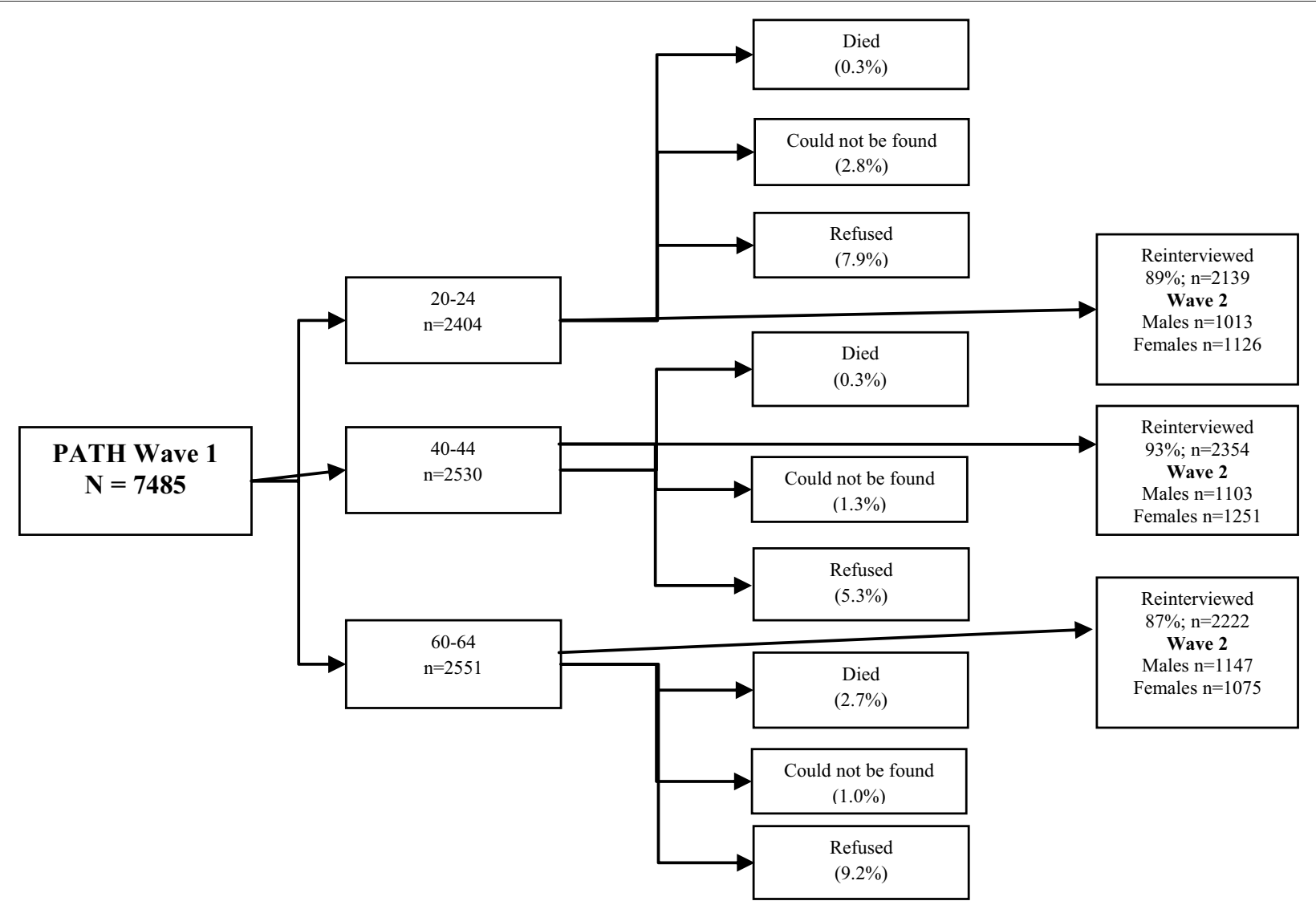

Figure 1 Flowchart showing participation rates for PATH Wave 1 and Wave 2.

'New suicidality' encompassed participants reporting no serious suicidality at baseline, but serious suicidality at follow-up. 'Remission' comprised serious suicidality at baseline, but not at follow-up. Continued serious suicidality and no serious suicidality included those who report serious suicidality at both or neither data collection points, respectively.

\section{Inferential statistics}

Participants reporting experience of suicidality during the 12-months prior to baseline were omitted $(n=609)$. Binary multivariate logistic regression (SPSS Version 12) predicted serious suicidality at follow-up from simultaneously-entered variables associated with suicidality at baseline in those without previous suicidality. The predictor variables comprised age group, gender, marital status, employment status, years of education to highest qualification, frequency of marijuana use, frequency of alcohol use, mastery, childhood adversity, physical medical condition, depression and anxiety, and life events in previous six months. The interaction between age and gender was assessed by entering the term concurrently with all the other predictors.

\section{Results}

\section{Sociodemographic trends}

Significant changes to marital status statistics were apparent at follow-up, as shown in Table 1. More participants were married ( $46.8 \%$ to $53.2 \%$ ) due to a large proportion of the 20s group marrying after the baseline interview, proportions of separated/divorced/widowed respondents (44.5\% to $55.5 \%$ ) were consistent across age groups, and fewer people remained never married $(62.1 \%$ to $37.9 \%)$. Less people remained in paid employment $(51.5 \%$ to $48.5 \%)$ as a large proportion of the 60 s group withdrew from the labour force. The sample continued to spend time in education after the baseline interview (14.2 years to 14.5 years), a statistic mainly driven by the $20 \mathrm{~s}$ group.

\section{Comparison of annual prevalence}

Overall, suicidal ideation significantly decreased from baseline to follow-up ( $8.2 \%$ to $6.1 \%, \mathrm{p}<0.001$; Table 2$)$. All age-by-gender categories replicate this downward trend. Similarly, the prevalence of suicide attempt significantly fell $(0.8 \%$ to $0.5 \%, \mathrm{p}<0.05)$, but females aged $40-49$ represented the only group to show a notable reduction $(1.1 \%$ to $0.4 \%, \mathrm{p}<0.05)$. 
Table 1: Unadjusted Comparisons between Wave 1 and Wave 2 participants for age groups within gender sociodemographic characteristics $(\mathrm{N}=6,648)$

\begin{tabular}{|c|c|c|c|c|c|c|}
\hline \multirow{3}{*}{$\begin{array}{l}\text { Age Groups } \\
\text { Wave }\end{array}$} & \multicolumn{6}{|c|}{ Males } \\
\hline & \multicolumn{2}{|c|}{$20 s$} & \multicolumn{2}{|c|}{$40 \mathrm{~s}$} & \multicolumn{2}{|c|}{$60 s$} \\
\hline & W1 & W2 & W1 & W2 & W1 & W2 \\
\hline \multicolumn{7}{|l|}{ Marital status, \%\#(AR) } \\
\hline Married/de facto & $18.3(-14.9)$ & 49.8 & $81.9(0.5)$ & 81.1 & $88.6(0.9)$ & 87.4 \\
\hline Sep/div/widowed & $0.3(-5.2)$ & 3.5 & $9.3(-1.5)$ & 11.2 & $9.8(-0.9)$ & 11.0 \\
\hline Never married & $81.4(16.2)$ & 46.8 & $8.9(-1.0)$ & 7.7 & $1.6(0.0)$ & 1.6 \\
\hline \multicolumn{7}{|l|}{ Employment, \%\#(AR) } \\
\hline Employed & $86.2(-4.1)$ & 91.9 & $95.7(2.2)$ & 93.6 & $50.6(8.9)$ & 32.2 \\
\hline Not employed & $6.5(2.3)$ & 4.2 & $1.9(0.0)$ & 1.9 & $1.5(3.5)$ & 0.2 \\
\hline Not in labour force & $7.4(3.3)$ & 4.0 & $2.4(-2.7)$ & 4.5 & $47.9(-9.5)$ & 67.6 \\
\hline \multicolumn{7}{|l|}{ Education mean, (SE) ‡ } \\
\hline \multirow[t]{2}{*}{ Number of years to highest qualification } & $14.1(0.04)$ & $14.7(0.10)^{* * *}$ & $14.7(0.07)$ & $14.9(0.10)$ & $14.4(0.08)^{*}$ & $14.6(0.13)$ \\
\hline & \multicolumn{6}{|c|}{ Females } \\
\hline Age Groups & \multicolumn{2}{|c|}{$20 s$} & \multicolumn{2}{|c|}{$40 \mathrm{~s}$} & \multicolumn{2}{|c|}{$60 \mathrm{~s}$} \\
\hline Wave & w1 & W2 & W1 & W2 & W1 & W2 \\
\hline \multicolumn{7}{|l|}{ Marital status, \%\#(AR) } \\
\hline Married/de facto & $29.1(-13.2)$ & 56.7 & $77.4(1.3)$ & 75.2 & $69.5(1.3)$ & 66.8 \\
\hline Sep/div/widowed & $1.8(-4.8)$ & 5.7 & $15.6(-1.8)$ & 18.2 & $27.4(-1.5)$ & 30.3 \\
\hline Never married & $69.1(8.2)$ & 37.5 & $7.0(-0.4)$ & 6.6 & $3.1(0.3)$ & 2.9 \\
\hline \multicolumn{7}{|l|}{ Employment, \%\#(AR) } \\
\hline Employed & $86.1(-0.3)$ & 86.5 & $86.1(-0.3)$ & 86.5 & $33.3(7.1)$ & 19.7 \\
\hline Not employed & $2.5(0.7)$ & 2.1 & $2.5(0.7)$ & 2.1 & $0.7(2.1)$ & 0.1 \\
\hline Not in labour force & $10.6(-0.9)$ & 11.7 & $11.4(0.0)$ & 11.4 & $66.1(-7.3)$ & 80.2 \\
\hline \multicolumn{7}{|l|}{ Education mean, (SE) ₹ } \\
\hline Number of years to highest qualification & $14.4(0.05)$ & $15.1(0.12)^{* * *}$ & $14.3(0.06)$ & $14.6(0.12)$ & $13.5(0.08)$ & $13.8(0.18)$ \\
\hline
\end{tabular}


Table 2: Annual prevalence rates of suicidal ideation and suicide attempt in the PATH Through Life Project $(N=6,666)$

\begin{tabular}{|c|c|c|c|c|c|}
\hline \multirow[b]{2}{*}{ Gender } & \multirow[b]{2}{*}{ Age Group } & \multicolumn{2}{|c|}{ Suicidal ideation \% } & \multicolumn{2}{|c|}{ Suicide attempts \% (n) } \\
\hline & & Wave 1 & Wave 2 & Wave 1 & Wave 2 \\
\hline Total & & $8.2(609)$ & $6.1^{* * *}(406)$ & $0.8(60)$ & $0.5 *(34)$ \\
\hline \multirow[t]{3}{*}{ Males } & $20 \mathrm{~s}$ & $12.6(145)$ & $9.3^{* *}(94)$ & $1.2(14)$ & $1.0(10)$ \\
\hline & $40 \mathrm{~s}$ & $8.9(105)$ & $6.3^{* * *}(69)$ & $0.7(8)$ & $0.5(5)$ \\
\hline & $60 \mathrm{~s}$ & $3.9(51)$ & $2.6^{* *}(30)$ & $0.2(2)$ & $0.1(1)$ \\
\hline \multirow[t]{3}{*}{ Females } & $20 \mathrm{~s}$ & $13.4(165)$ & $9.9^{* *}(110)$ & $1.6(20)$ & $1.0(11)$ \\
\hline & $40 \mathrm{~s}$ & $8.8(117)$ & $6.8^{* *}(85)$ & $1.2(16)$ & $0.4^{*}(5)$ \\
\hline & $60 \mathrm{~s}$ & $2.1(26)$ & $1.7(18)$ & 0 & $0.2(2)$ \\
\hline
\end{tabular}

Significant difference between Wave 1 and $2,{ }^{*} p<0.05,{ }^{* *} p<0.01,{ }^{* * *} p<0.001$, McNemar's Test.

\section{New serious suicidality and remissions}

Follow-up data provided the opportunity to record numbers of participants indicating new, and remissions from serious suicidality (see Table 3 ). At follow-up 3.4\% ( $\mathrm{n}=$ 226) of the sample reported new occurrences of serious suicidality, while $2.7 \%(\mathrm{n}=179)$ continued to experience serious suicidality. However, $5.2 \%$ of the PATH sample indicated no serious suicidality currently occurred, and the vast majority re-interviewed participants had no serious suicidality at baseline or follow-up $(88.7 \%, \mathrm{n}=5,915)$. Table 3 shows that, overall, experience of serious suicidality was highest among females aged 20-29, whereas females in their $60 \mathrm{~s}$ had fewest reports of serious suicidality (no suicidality: $97.0 \%, \mathrm{n}=1,026$ ).

\section{Prediction of serious suicidality}

After excluding participants who reported suicidality during the 12-months prior to baseline, baseline-measured variables were entered simultaneously into a binary multivariate logistic regression model in which serious suicidality at follow-up comprised the outcome measure. Importantly, there were significant age-related differences in the proportions of participants omitted by this process (25.7\% for 20s group, $19.1 \%$ for 40 s group, and 9.7 for 60s group; $\left.X^{2}[2]=189.9, \mathrm{p}<0.0001\right)$.

Results showed a significant main effect for marital status (Wald $X^{2}[2]=9.03, \mathrm{p}<0.05$ ), with participants developing serious suicidality after baseline more likely to be divorced $/$ separated $/$ widowed $(\mathrm{OR}=1.70,95 \% \mathrm{CI}=1.13$, 2.27 ), or never married $(\mathrm{OR}=2.07,95 \% \mathrm{CI}=1.50,2.65)$. These participants had also greater odds of encountering adversity in their childhood (OR $=1.11,95 \% \mathrm{CI}=1.04$, 1.17), and experiencing higher levels of depression/anxiety $(\mathrm{OR}=1.10,95 \% \mathrm{CI}=1.05,1.14)$. The sample was split into age-by-gender groups as the interaction was previously found to be significant $[6,26]$.

Table 3: New, continued, and remission from serious suicidality at follow-up $(N=6,666)$

Serious Suicidality

\begin{tabular}{|c|c|c|c|c|c|}
\hline Gender & Age Group & New suicidality \% (n) & Remission \% (n) & Continued suicidality \% (n) & No suicidality \% (n) \\
\hline Total & & $3.4(226)$ & $5.2(346)$ & $2.7(179)$ & $88.7(5915)$ \\
\hline \multirow[t]{4}{*}{ Males } & & $3.2(104)$ & $5.2(167)$ & $2.7(88)$ & $88.9(2882)$ \\
\hline & $20 \mathrm{~s}$ & $5.3(53)$ & $7.8(78)$ & $4.1(41)$ & $82.9(837)$ \\
\hline & $40 \mathrm{~s}$ & $3.1(34)$ & $5.6(61)$ & $3.1(34)$ & $88.2(969)$ \\
\hline & $60 \mathrm{~s}$ & $1.5(17)$ & $2.5(28)$ & $1.1(13)$ & $94.9(1076)$ \\
\hline \multirow[t]{4}{*}{ Females } & & $3.6(122)$ & $5.2(179)$ & $2.7(91)$ & $88.6(3033)$ \\
\hline & $20 \mathrm{~s}$ & $5.5(60)$ & $8.8(97)$ & $4.5(50)$ & $81.3(912)$ \\
\hline & $40 \mathrm{~s}$ & $4.0(49)$ & $5.5(68)$ & $2.9(36)$ & $87.7(1093)$ \\
\hline & $60 \mathrm{~s}$ & $1.2(13)$ & $1.3^{* *}(14)$ & $0.5^{* *}(5)$ & $97.0^{* *}(1028)$ \\
\hline
\end{tabular}

Significant difference between males and females (total, 20s, 40s, and 60s), ${ }^{*} p<0.05,{ }^{* *} p<0.01,{ }^{* * *} p<0.001$, Chi-square Test. 


\section{Age and gender}

Among the males 20s group, females 20s and 60s group depression/anxiety significantly predicted serious suicidality $(\mathrm{OR}=1.14,95 \% \mathrm{CI}=1.02,1.26 ; \mathrm{OR}=1.09,95 \%$ $\mathrm{CI}=1.00,1.18$; OR $=1.28,95 \% \mathrm{CI}=1.04,1.52$, respectively; Table 4). Other significant predictors appeared more group-specific. Females aged in their 20 s had notably higher odds of suicidal behaviour if suffering a physical medical condition $(\mathrm{OR}=3.18,95 \% \mathrm{CI}=2.09,4.26)$ or not married at baseline $(\mathrm{OR}=4.17,95 \% \mathrm{CI}=3.11,5.23)$. When not in the labour force at baseline, the males $40 \mathrm{~s}$ group had greater odds of subsequent serious suicidality $(\mathrm{OR}=4.08,95 \% \mathrm{CI}=1.68,6.48)$.

\section{Discussion}

Although longitudinal methodology confounds developmental age changes with period effects, and comparisons between age groups confound developmental age variation with cohort differences[27], there are many advantages of this approach[28]. These include the capacity to compare baseline and follow-up rates of suicidal ideation, and suicide attempt and provide insight into the influence of distal predictor impact on becoming seriously suicidal.

\section{Prevalence and trends}

Annual prevalence rates of suicidal ideation fell from $8.2 \%$ to $6.1 \%$, although the decline among the 60 s group was not significant. Further, while overall suicide attempts significantly reduced from $0.8 \%$ to $0.5 \%$ at follow-up, only the females 40 s group reported notably fewer attempts over time. Though it is likely that attrition bias resulted in Wave 2 rates being underestimated, feasible interpretations of the overall decrease in suicidality may encompass the PATH project acting as an intervention, motivating participants to visit their doctor[29], or an overall effect of participants ageing (akin to rates of depression decreasing with age). Other plausible explanations encompass the reduced levels of suicidality being artefactual, as there is the potential for participants to present themselves more positively at re-test[30-32]; and, the National suicide prevention strategies functioning to produce the apparent decline in rates [7].

The analysis of new suicidality showed approximately one third of the male 20s and the female 60s groups reporting serious suicidality were new occurrences. Table 3 clearly illustrates that the youngest cohort has the largest proportion of 'new suicidality', and the largest proportion of 'remissions'. Putatively, for many young adults, active suicidality occurs in response to an acute stressor[33,34]. If the crisis is resolved, or the individual learns to cope with their new reality, suicidal cognitions and behaviours generally dissipate[35]. Nevertheless, some participants experience their suicidality on a continual basis, perhaps co-morbidly with another mental health problem such as depression or anxiety[11]. Rates for suicidality echo trends found for depression/anxiety: decrease with age, and accord with existing literature[26,36] (see Table 2).

\section{Prediction of serious suicidality at follow-up}

The regression model adjusted for the influence of other covariates, tested for interactions between age and gender, and revealed the need for separate age-by-gender models. Analysis conducted on the full sample indicated divorced/separated/widowed participants, never married (and not partnered) at baseline participants, those with more difficult childhoods, and with greater levels of depression/anxiety were all more likely to report serious suicidality four years later. These findings are consistent with existing literature $[8,9,11,12]$, but longitudinal data extend current knowledge. Results suggest that the aforementioned variables remain risk factors in adults throughout the life course, even in the absence of suicidal symptoms. This investigation revealed no main effect for age, most likely a result of the greater prevalence of ideation among young PATH participants at baseline, who were subsequently excluded from the analysis. The significant age-by-gender interaction in the current study affirm recent investigations $[6,26]$ that highlight benefits of considering suicidality by age and gender categories. Some overlap with the total sample was evident, however, analyses of age-by-gender sub-groups revealed several highly specific predictors of serious suicidality. Noteworthy findings will be discussed by the relevant predictor category.

\section{Demographics}

Previous research concords with the present findings indicating those never married (nor partnered) have increased probability of experiencing serious suicidality $[37,38]$. However, this analysis further stresses the association between being unpartnered and subsequent serious suicidal behaviour among unpartnered young females. Indeed, this lack of partnership may be felt keenly as many of their similarly-aged counterparts are in relationships, as illustrated by Table 1. It is also possible that the inflated odds of suicidal behaviour in young, never married females are symptomatic of insufficient social support[37,39]. Casey et al.'s[40] research more broadly validates the present findings as they found participants from a general population sample with 'people to count on' or were 'shown concern by others' were onethird and two-thirds less likely have suicidal thoughts, respectively.

A particularly noteworthy finding relates to the males 40s group not previously in the labour force nor suicidal at baseline experiencing a four-fold increase in serious suicidality at follow-up. Fairweather et al. [6] identified a nine-fold increase in suicide attempts among unem- 
Table 4: Prediction of serious suicidality at follow-up among participants reporting no suicidality at baseline $(\mathrm{N}=6,057)$

\begin{tabular}{|c|c|c|c|}
\hline \multirow[b]{2}{*}{ Variables entered } & \multicolumn{3}{|c|}{ Males OR (95\% Cl) } \\
\hline & $20 s$ & $40 \mathrm{~s}$ & $60 s$ \\
\hline \multicolumn{4}{|l|}{ Demographics } \\
\hline \multicolumn{4}{|l|}{ Marital status } \\
\hline Married/partnered (ref) & 1.00 & 1.00 & 1.00 \\
\hline Divorced/Separated/Widowed & $\wedge$ & $0.62(0.0,2.82)$ & $4.29(0.0,8.75)$ \\
\hline Never married & $1.33(0.23,2.44)$ & $0.83(0.0,3.51)$ & $\wedge$ \\
\hline Years studied to highest qualification & $0.73(0.44,1.02)$ & $1.10(0.88,1.32)$ & 0.99 \\
\hline Parent of (a) child(ren) & $0.52(0.0,2.70)$ & $1.35(0.0,3.20)$ & $\wedge$ \\
\hline \multicolumn{4}{|l|}{ Employment } \\
\hline Employed & 1.00 & 1.00 & 1.00 \\
\hline Not employed & $1.28(0.0,2.67)$ & $\wedge$ & $\wedge$ \\
\hline Not in labour force & $0.52(0.0,2.62)$ & $4.08^{* *}(1.68,6.48)$ & $0.49(0.0,1.63)$ \\
\hline \multicolumn{4}{|l|}{ Relationships and Life Stressors } \\
\hline Number of life events & $1.12(0.88,1.36)$ & $1.13(0.73,1.52)$ & $1.24(0.0,2.51)$ \\
\hline Childhood adversity & $1.08(0.88,1.27)$ & $0.90(0.66,1.14)$ & $1.08(0.0,2.21)$ \\
\hline Negative interactions with friends & $1.05(0.83,1.27)$ & $1.20(0.88,1.53)$ & $0.89(0.0,1.79)$ \\
\hline \multirow[t]{2}{*}{ Negative interactions with family } & $0.90(0.69,1.11)$ & $1.09(0.82,1.37)$ & $0.95(0.0,1.91)$ \\
\hline & \multicolumn{3}{|c|}{ Females OR $(95 \% \mathrm{Cl})$} \\
\hline Variables entered & $20 s$ & $40 \mathrm{~s}$ & $60 \mathrm{~s}$ \\
\hline \multicolumn{4}{|l|}{ Demographics } \\
\hline \multicolumn{4}{|l|}{ Marital status } \\
\hline Married/partnered (ref) & 1.00 & 1.00 & 1.00 \\
\hline Divorced/Separated/Widowed & $\wedge$ & $1.75(0.0,3.62)$ & $2.83(0.50,5.17)$ \\
\hline Never married & $4.17^{* * *}(3.11,5.23)$ & $1.05(0.0,2.58)$ & $\wedge$ \\
\hline Years studied to highest qualification & $1.08(0.83,1.33)$ & $1.01(0.0,2.19)$ & $0.82(0.40,1.25)$ \\
\hline Parent of (a) child(ren) & $1.59(0.39,2.80)$ & $0.40(0.0,1.57)$ & $\wedge$ \\
\hline \multicolumn{4}{|l|}{ Employment } \\
\hline Employed & 1.00 & 1.00 & 1.00 \\
\hline Not employed & $0.63(0.0,2.76)$ & $\wedge$ & $\wedge$ \\
\hline Not in labour force & $2.12(0.93,3.31)$ & $0.79(0.0,2.12)$ & $0.45(0.0,2.10)$ \\
\hline \multicolumn{4}{|l|}{ Relationships and Life Stressors } \\
\hline Number of life events & $1.09(0.85,1.33)$ & $0.89(0.0,1.91)$ & $0.91(0.06,1.75)$ \\
\hline Childhood adversity & $1.06(0.89,1.22)$ & $1.10(0.0,2.43)$ & $1.33(0.98,1.68)$ \\
\hline Negative interactions with friends & $1.00(0.78,1.23)$ & $0.84(0.0,1.77)$ & $0.93(0.41,1.45)$ \\
\hline \multirow[t]{2}{*}{ Negative interactions with family } & $0.88(0.70,1.06)$ & $0.95(0.0,2.04)$ & $1.13(0.70,1.57)$ \\
\hline & \multicolumn{3}{|c|}{ Males OR (95\% Cl) } \\
\hline Variables entered & $20 s$ & $40 \mathrm{~s}$ & $60 s$ \\
\hline \multicolumn{4}{|l|}{ Health \& Substance use } \\
\hline Physical medical condition & $1.96(0.34,3.57)$ & $0.82(0.0,2.15)$ & $0.61(0.0,1.75)$ \\
\hline Depression \& Anxiety & $1.02(0.91,1.12)$ & $1.14^{*}(1.02,1.26)$ & $1.08(0.0,2.26)$ \\
\hline
\end{tabular}


Table 4: Prediction of serious suicidality at follow-up among participants reporting no suicidality at baseline $(\mathrm{N}=6,057)(\mathrm{Con}$ tinued)

\begin{tabular}{|c|c|c|c|}
\hline Current smoker & $0.71(0.0,1.59)$ & $0.83(0.0,2.20)$ & $1.05(0.0,2.72)$ \\
\hline \multicolumn{4}{|l|}{ Marijuana use } \\
\hline $\begin{array}{l}\text { Don't use (includes previous users; reference } \\
\text { group) }\end{array}$ & 1.00 & 1.00 & 1.00 \\
\hline Once or twice per year & $1.88(0.92,2.85)$ & $\wedge$ & $\wedge$ \\
\hline Once every one to four months & $1.22(0.0,2.46)$ & $\wedge$ & $\wedge$ \\
\hline At least once per week & $1.60(0.31,2.90)$ & $\wedge$ & $\wedge$ \\
\hline \multicolumn{4}{|l|}{$\mathrm{AUDIT}^{+}$} \\
\hline Abstain & 1.00 & 1.00 & 1.00 \\
\hline Occasional/light drinking & $0.61(0.0,1.92)$ & $0.75(0.0,2.38)$ & $1.06(0.0,2.78)$ \\
\hline Medium level drinking & $0.76(0.0,2.37)$ & $1.42(0.0,3.21)$ & $1.19(0.0,3.21)$ \\
\hline Hazardous/harmful drinking & $2.00(0.25,3.74)$ & $1.50(0.0,4.15)$ & $\wedge$ \\
\hline \multicolumn{4}{|l|}{ Personality } \\
\hline Psychoticism & $1.03(0.81,1.24)$ & $1.06(0.77,1.34)$ & $1.37(0.0,2.90)$ \\
\hline \multirow[t]{2}{*}{ Mastery } & $0.96(0.84,1.09)$ & $1.00(0.85,1.16)$ & $0.97(0.0,2.01)$ \\
\hline & \multicolumn{3}{|c|}{ Females OR (95\% Cl) } \\
\hline Variables entered & $20 s$ & $40 s$ & $60 \mathrm{~s}$ \\
\hline \multicolumn{4}{|l|}{ Health \& Substance use } \\
\hline Physical medical condition & $3.18^{* * *}(2.09,4.26)$ & $1.45(0.0,3.01)$ & $0.43(0.0,2.32)$ \\
\hline Depression \& Anxiety & $1.09 *(1.00,1.18)$ & $1.01(0.0,2.26)$ & $1.28^{*}(1.04,1.52)$ \\
\hline Current smoker & $0.98(0.12,1.84)$ & $1.39(0.0,2.92)$ & $0.86(0.0,3.55)$ \\
\hline \multicolumn{4}{|l|}{ Marijuana use } \\
\hline $\begin{array}{l}\text { Don't use (includes previous users; reference } \\
\text { group) }\end{array}$ & 1.00 & 1.00 & 1.00 \\
\hline Once or twice per year & $1.03(0.06,2.00)$ & $3.60(0.0,7.54)$ & $\wedge$ \\
\hline Once every one to four months & $0.68(0.0,2.22)$ & $\wedge$ & $\wedge$ \\
\hline At least once per week & $1.72(0.0,3.45)$ & $\wedge$ & $\wedge$ \\
\hline \multicolumn{4}{|l|}{ AUDIT $^{\dagger}$} \\
\hline Abstain & 1.00 & 1.00 & 1.00 \\
\hline Occasional/light drinking & $1.00(0.0,2.17)$ & $0.83(0.0,2.20)$ & $1.23(0.0,3.38)$ \\
\hline Medium level drinking & $0.57(0.0,2.25)$ & $0.98(0.0,2.52)$ & $0.84(0.0,3.54)$ \\
\hline Hazardous/harmful drinking & $\wedge$ & $0.61(0.0,2.57)$ & $\wedge$ \\
\hline \multicolumn{4}{|l|}{ Personality } \\
\hline Psychoticism & $1.12(0.85,1.39)$ & $0.83(0.0,1.74)$ & $1.61(0.92,2.30)$ \\
\hline Mastery & $1.04(0.91,1.17)$ & $0.89(0.0,1.95)$ & $0.69(0.26,1.12)$ \\
\hline
\end{tabular}

OR: Odds Ratios, 95\% Confidence Interval, ${ }^{*} p<0.05,{ }^{* *} p<0.01,{ }^{* * *} p<0.001$

$\wedge$ parameter not available due to small cell size

${ }^{+}$AUDIT is the Alcohol Use Disorders Identification Test

ployed, ideating 40-44 year olds, but the present longitudinal methodology shows that non-participation in employment predates suicidality. This investigation emphasises the salience of employment as a protective factor against the development of suicidality in this group. Putatively, being employed is vital to males in their 40s for a number of reasons including providing financial support to their (often young) families, playing an important role in establishing and promoting a sense of male identity and purpose in life[41], and, the work place may afford males with social support and contact[42], shown to be vital in times of stress. 


\section{Health and substance use}

Overall, depression/anxiety robustly predicted serious suicidality at follow-up. In addition to middle-aged males, the female 20 s and 60 s groups showed a greater likelihood of serious suicidality if initially suffering depression/anxiety. This emphasises the major role of depression/anxiety in subsequent manifestations of suicidal behaviours. While consistent with existing literature[43-45], this analysis highlights the distal relationship between depression/anxiety and suicidality, underscoring the need for prompt diagnosis and treatment of affective syndromes ahead of further stressors/events potentially triggering suicidal behaviour.

The majority of investigations considering physical ill health in relation to suicidality adjust for age and/or gender, utilise samples with greater mean ages[46,47] and commonly focus on completed suicides[48]. Two rare community-based cohort studies (utilising baseline data) indicate that likelihood of suicidal behaviour is significantly elevated among older persons suffering physical illness. De Leo et al.'s[46] European-wide study found $20 \%$ of those reporting suicidal behaviour when suffering a physical illness or disability indicate that their ill health had a major role in activating their suicidality. Fairweather et al. [6] identified that male suicide ideators with physical medical conditions were more likely to attempt suicide than their physically-well counterparts. Uniquely, this paper finds young females reporting no suicidality at baseline, but suffering physical medical conditions (including cancer), experience serious suicidality at threefold the physically well rate at follow-up. The impact of physical illness was larger than symptoms of depression/ anxiety. Physical illness functioning as a distal risk may reflect a deterioration in quality of life over time (e.g., as cancer advances), or an increase in pain levels $[49,50]$. Nevertheless, low cell numbers require this interpretation to be viewed cautiously.

\section{Strengths and limitations}

The design of this investigation has a number of noteworthy strengths including longitudinal and the PATH survey methodology, the large sample, and equivalent proportions of both gender and age cohorts. However, aside from the longitudinal study confounds, limitations include the potential for participants who reported no suicidality in the previous 12 months, to have experienced suicidality prior to this period. It is possible that some individuals were considered non-ideators and consequently included in the baseline sample of non-ideator/ plan/attempters. In addition to the survey having restricted age bands, there were three years dividing the data collection points and some categories had small cell size potentially impacting the capacity to detect effects.
The information provided was also retrospective and self-reported.

\section{Conclusions}

Although follow-up prevalence rates of suicidal ideation, suicide attempt and other statistics concerning serious suicidality provide valuable information, the main focus of the paper was to identify factors predictive of serious suicidality at follow-up among those who initially reported no suicidality. This investigation demonstrates the presence of age and gender differences in factors distally predictive of serious suicidality. Consideration of these basic demographic characteristics may help to focus suicidal symptom identification in clinical settings, and contributes to the level of specificity that prevention and intervention programs are currently argued to be lacking. Future research opportunities remain to be explored which take into account change in the proximal predictors of suicidality and the presence of suicidality.

\section{Competing interests}

The authors declare that they have no competing interests.

\section{Authors' contributions}

All authors have read and approved the final manuscript. AKF-S conceived the study, performed the majority of the statistical analysis and drafted the manuscript. KJA was involved in critically revising the manuscript for important intellectual content and data acquisition. AS performed an essential component of the data analysis, and contributed to the method section. BR critically reviewed the manuscript and was also involved in data acquisition.

\section{Acknowledgements}

We wish to thank Trish Jacomb, Karen Maxwell and the PATH interviewers for their assistance with the study. Funding was provided by National Health and Medical Research Council Grants 179805 and 79839, a grant from the AlcoholRelated Medical Research Grant Scheme of the Australian Brewers' Foundation and a grant from the Australian Rotary Health Research Fund. Associate Professor Kaarin Anstey was supported by National Health and Medical Research Council Fellowship Grant (366756). At the time this research was conducted, Dr Kate Fairweather-Schmidt was partially supported by an AFFIRM scholarship. We would like to acknowledge Professor Tony Jorm, Professor Helen Christensen and Professor Bryan Rodgers, who are also chief investigators of the PATH Through Life Project.

\section{Author Details}

1Freemasons Foundation Centre for Men's Health, The University of Adelaide, Adelaide, 5005, South Australia, ${ }^{2}$ Centre for Mental Health Research, The Australian National University, Canberra, 0200, Australian Capital Territory, 3Department of Epidemiology and Public Health, Yong Loo Lin School of Medicine, National University of Singapore, 16 Medical Drive, 117597, Singapore and ${ }^{4}$ Australian Demographic \& Social Research Institute, The Australian National University, Canberra, 0200, Australian Capital Territory

Received: 25 November 2009 Accepted: 9 June 2010

Published: 9 June 2010

\section{References}

1. Commonwealth Department of Health and Aged Care: LIFE: areas for action. Canberra: Commonwealth of Australia; 2000.

2. Australian Bureau of Statistics: 3303.0 Causes of Death. Canberra 2006.

3. Johnston AK, Pirkis JE, Burgess PM: Suicidal thoughts and behaviours among Australian adults: findings from the 2007 National Survey of Mental Health and Wellbeing. Aust N Z J Psychiatry 2009, 43:635-643. 
4. Dixon WA, Heppner P, Rudd M: Problem-solving appraisal, hopelessness, and suicide ideation: Evidence for a mediational model. J Couns Psychol 1994, 41:91-98.

5. Moscicki EK: Epidemiology of suicidal behavior. Suicide Life Threat Behav 1995, 25:22-35

6. Fairweather AK, Anstey KJ, Rodgers B, Butterworth P: Factors distinguishing suicide attempters from suicide ideators in a community sample: Social issues and physical health problems. Psychol Med 2006, 36:1235-1246.

7. Morrell S, Page AN, Taylor RJ: The decline in Australian young male suicide. Soc Sci Med 2007, 64:747-754.

8. De Leo D, Cerin E, Spathonis K, Burgis S: Lifetime risk of suicide ideation and attempts in an Australian community: Prevalence, suicidal process, and help-seeking behaviour. J Affect Disord 2005, 86:215-224.

9. Fanous AH, Prescott CA, Kendler KS: The prediction of thoughts of death or self-harm in a population-based sample of female twins. Psychol Med 2004, 34:301-312.

10. Qin P, Agerbo E, Mortensen PB: Suicide risk in relation to socioeconomic, demographic, psychiatric, and familial factors: a national registerbased study of all suicides in Denmark 1981-1997. Am J Psychiatry 2003, 160:765-772.

11. Gunnell D, Harbord R, Singleton N, Jenkins R, Lewis G: Factors influencing the development and amelioration of suicidal thoughts in the general population. Br J Psychiatry 2004, 185:385-393.

12. Hintikka J, Pesonen T, Saarinen P, Tanskanen A, Lehtonen J, Viinamäki H: Suicidal ideation in the Finnish general population: a 12-month followup study. Soc Psychiatry Psychiatr Epidemiol 2001, 36:590-594.

13. Anstey KJ, Hofer SM: Longitudinal designs, methods and analysis in psychiatric research. Aust NZJ Psychiatry 2004, 38:93-104.

14. Jorm AF, Anstey KJ, Christensen H, Rodgers B: Gender differences in cognitive abilities: the mediating role of health state and health habits. Intelligence 2004, 32:7-23.

15. Goldberg D, Bridges K, Duncan-Jones P, Grayson D: Detecting anxiety and depression in general medical settings. Br Med J 1988, 297:897-899.

16. Saunders JB, Aasland OG, Babor TF, De La Fuente JR, Grant M: Development of the Alcohol Use Disorders Identification Test (AUDIT): WHO collaborative project on early detection of persons with harmful alcohol consumption. Addiction 1993, 88:791-804

17. Jorm AF, Rodgers B, Jacomb PA, Christensen H, Henderson S, Korten AE: Smoking and mental health: results from a community survey. Med J Aust 1999, 170:74-77.

18. Social Science Data Archives: National Campaign Against Drug Abuse social issues survey. Canberra: The Australian National University; 1993.

19. Christensen H, Jorm AF, Henderson S, Mackinnon AJ, Korten AE, Scott LR: The relationship between health and cognitive functioning in a sample of elderly people in the community. Age Ageing 1994, 23:204-212.

20. Rosenman S, Rodgers B: Childhood adversity in an Australian population. Soc Psychiatry Psychiatr Epidemiol 2004, 39:695-702.

21. Brugha TS, Cragg D: The List of Threatening Experiences: the reliability and validity of a brief life events questionnaire. Acta Psychiatr Scand $1990,82: 77-81$

22. Schuster TL, Kessler RC, Aseltine RHJ: Supportive interactions, negative interactions and depressed mood. Am J Community Psychol 1990, 18:423-437.

23. Eysenck SBG, Eysenck HJ, Barrett P: A revised version of the psychoticism scale. Pers Individ Dif 1985, 6:21-29.

24. Pearlin LI, Lieberman MA, Menaghan EG, Mullan JT: The stress process. J Health Soc Behav 1981, 22:337-356

25. Lindelow M, Hardy R, Rodgers B: Development of a scale to measure symptoms of anxiety and depression in the general population: the psychiatric symptom frequency scale. J Epidemiol Community Health 1997, 51:549-557.

26. Fairweather AK, Anstey KJ, Rodgers B, Jorm AF, Christensen H: Age and gender differences among Australian suicide ideators: prevalence and correlates. J Nerv Ment Dis 2007, 195:130-136.

27. Twisk JWR: Applied longitudinal data analysis for epidemiology. Cambridge: Cambridge University Press; 2003.

28. Ruspini E: Introduction to longitudinal research. Londone: Routledge; 2002

29. Parslow RA, Jorm AF, Christensen H, Rodgers B: Use of medical services after participation in a community-based epidemiological health survey. Soc Psychiatry Psychiatr Epidemiol 2004, 39:311-317.
30. Jorm AF, Duncan-Jones P, Scott R: An analysis of the re-test artefact in longitudinal studies of psychiatric symptoms and personality. Psychol Med 1989, 19:487-493.

31. Arrindell WA: Changes in waiting-list patients over time: data on some commonly-used measures. Beware! Behav Res Ther 2001, 39:1227-1247.

32. Henderson S: Social relationships, adversity and neurosis: An analysis of prospective observations. Br J Psychiatry 1981, 138:391-398.

33. Donald M, Dower J, Correa-Velez I, Jones M: Risk and protective factors for medically serious suicide attempts: a comparison of hospital-based with population-based samples of young adults. Aust NZ J Psychiatry 2006, 40:87-96

34. Rich CL, Warstadt GM, Nemiroff RA, Fowler RC: Suicide, stressors, and the life cycle. Am J Psychiatry 1991, 148:524-527.

35. Kerr DCR, Owen LD, Capaldi DM: Suicidal ideation and its recurrence in boys and men from early adolescence to early adulthood: An event history analysis. J Abnorm Psychol 2008, 117:625-636.

36. Bille-Brahe U: The role of sex and age in suicidal behavior. Acta Psychiatr Scand Supp/ 1993, 371:21-27.

37. Pirkis J, Burgess P, Dunt D: Suicidal Ideation and Suicide Attempts Among Australian Adults. Crisis 2000, 21:16-25.

38. Johnston A, Cooper J, Webb R, Kapur N: Individual- and area-level predictors of self-harm repetition. Br J Psychiatry 2006, 189:416-421.

39. Heikkinen $M$, Aro H, Lonnqvist J: Recent life events, social support and suicide. Acta Psychiatr Scand Suppl 1994, 377:65-72.

40. Casey PR, Dunn G, Kelly BD, Birkbeck G, Dalgard OS, Lehtinen V, Britta S, Ayuso-Mateos JL, Dowrick C: Factors associated with suicidal ideation in the general population. Br J Psychiatry 2006, 189:410-415.

41. Bernard J: The good-provider role: Its rise and fall. Am Psychol 1981, 36:1-12

42. Stravynski A, Boyer R: Loneliness in Relation to Suicide Ideation and Parasuicide: A Population-Wide Study. Suicide Life Threat Behav 2001 31:32-40

43. Beautrais AL, Joyce PR, Mulder RT, Fergusson DM, Deavoll BJ, Nightingale SK: Prevalence and comorbidity of mental disorders in persons making serious suicide attempts: a case-control study. Am J Psychiatry 1996 153:1009-1014

44. Goldney RD, Wilson D, Dal Grande E, Fisher LJ, McFarlane A: Suicidal ideation in a random community sample: attributable risk due to depression and psychosocial and traumatic events. Aust NZJ Psychiatry 2000, 3:98-106.

45. Lönnqvist J: Psychiatric aspects of suicidal behaviour: Depression. In The international handbook of suicide and attempted suicide Edited by: Hawton K, van Heeringen K. Chichester: John Wiley \& Sons, Ltd; 2000:107-120.

46. De Leo D, Scocco P, Marietta P, Schmidtke A, Bille-Brahe U, Kerkhof AJFM, Lonnqvist J, Crepet P, Salandar-Renberg E, Wasserman D, Michel K, Bjerke T: Physical illness and parasuicide: Evidence from the European Parasuicide Study Interview Schedule (EPSIS/WHO-EURO). Int $\mathrm{J}$ Psychiatry Med 1999, 29:149-163.

47. Goodwin RD, Kroenke K, Hoven CW, Spitzer RL: Major depression, physical illness, and suicidal ideation in primary care. Psychosom Med 2003, 65:501-505

48. Stenager EN, Stenager E: Physical illness and suicidal behaviour. In The international handbook of suicide and attempted suicide Edited by: Hawton K, van Heeringen K. New York: Wiley; 2000:405-420.

49. Treharne G, Lyons AC, Kitas GD: Suicidal ideation in patients with rheumatoid arthritis. Research may help identify patients at high risk [Comment]. BrMed J 2000, 321:1290.

50. Tang NKY, Crane C: Suicidality in chronic pain: a review of the prevalence, risk factors and psychological links. Psychol Med 2006, 36:575-586

Pre-publication history

The pre-publication history for this paper can be accessed here: http://www.biomedcentral.com/1471-244X/10/41/prepub

\section{doi: $10.1186 / 1471-244 X-10-41$}

Cite this article as: Fairweather-Schmidt et al., Baseline factors predictive of serious suicidality at follow-up: findings focussing on age and gender from a community-based study BMC Psychiatry 2010, 10:41 